\title{
Performance intensification of the coagulation process in drinking water treatment
}

\author{
Henry Heroe Mungondori', Tariro Annah Muchingami ${ }^{2}$, Raymond Tichawona Taziwa' and Nhamo Chaukura ${ }^{3}$ (i) \\ 'Department of Applied Science, Walter Sisulu University, Potsdam campus, Fort Jackson, Old King Williams Town Road, \\ East London, South Africa \\ ${ }^{2}$ Chemistry Department, University of Zimbabwe, PO Box MP167, Mt Pleasant, Harare, Zimbabwe \\ ${ }^{3}$ Department of Physical and Earth Sciences, Sol Plaatje University, Kimberley, South Africa
}

Surface water pollution has increased, owing to industrial development and population growth. Consequently, it is important to find alternative drinking water treatment strategies, which cater for changes in the quality of raw water. This study compared the efficiency of different coagulants in treating raw water that feeds a drinking water treatment plant (WTP). Using jar testing equipment and a number of physicochemical parameters, an investigation was conducted to establish optimum conditions for aluminium chloride (A), ferric chloride $(B)$, and chitosan (C), and their performance compared with aluminium sulphate (D), which is the coagulant used at the WTP. The turbidity removal efficiencies for the single coagulants were in the order: B (95.7\%) > A $(94.7 \%)>C(94.4 \%)$, at optimum coagulant doses of 60,50 , and $0.6 \mathrm{mg} / \mathrm{L}$, respectively. The coagulants achieved high removal efficiencies for turbidity, total dissolved solids (TDS), ultraviolet absorbance at $254 \mathrm{~nm}\left(\mathrm{UV}_{254}\right)$ and conductivity under acidic conditions. For dual coagulants, there was a gradual increase in the removal efficiencies of the tested parameters with increasing $\mathrm{pH}$. Combined coagulants were more effective compared to single coagulants, with highest removal efficiencies being exhibited by the $\mathrm{A} / \mathrm{C}$ combination. Overall, the coagulants proved to be suitable alternatives to $D$, since they had comparable performances.

\section{INTRODUCTION}

Factors such as population growth and economic development have resulted in elevated concentrations of pollutants in water bodies (Wang and Yang, 2016; Zhao et al., 2018; Lv et al., 2019). A variety of natural phenomena, like weathering, volcanicity, and human activities such as agriculture, mining, and manufacturing, produce pollutant-laden effluents that contaminate water bodies (Howladar, 2017; Rashid et al., 2019). Poor microbial water poses a threat to human health as this can potentially cause water-borne diseases like cholera, dysentery and typhoid (Wang and Yang, 2016; Rashid et al., 2019). In addition, toxic metals are cumulative toxins with public health risks. Consequently, surface water needs to be treated in order to produce safe drinking water.

The main stages of the conventional water treatment process are coagulation, flocculation, sedimentation, filtration, and disinfection (Bairwa, 2016). Coagulation is the destabilization of suspended particles using inorganic salts or polymers so that they may aggregate and form larger flocs (Renault et al., 2009; Wei et al., 2018). The coagulation process removes turbidity, organic particles, and suspended particles in water, and its efficiency depends on the characteristics of raw water, and the coagulant type and dosage used (Alshikh, 2007; Sillanpaa et al., 2018; Lv et al., 2019). Coagulation parameters such as $\mathrm{pH}$ and coagulant dose differ for each water source; hence the optimization of coagulants is necessary for full-scale implementation. The various pollutants in raw water can decrease the efficiency of coagulants; therefore it is important to characterize raw water so as to determine the optimum coagulation conditions (Yonge, 2011; Lv et al., 2019).

Iron-based and aluminium-based coagulants are commonly used in water treatment processes (Justina et al., 2018). In aqueous solution, iron and aluminium salts dissociate and react to form hydrolysis products that act as the coagulant species responsible for removing turbidity and colour (El Samrani et al., 2004). Other materials such as chitosan are efficient in removing turbidity and suspended particles in water (Renault et al., 2009; Loganathan et al., 2018). The advantage of each coagulant may be maximized by combining different coagulants (Renault et al., 2009). Comparison data on the performance of chitosan, aluminium chloride and ferric chloride, either singly or in combination, basing on real raw water quality in Zimbabwe is scarce. Hence there is a need to generate information based on raw water quality of local water treatment plants (WTPs). Owing to the vast pollutant burden in raw water, WTPs are operating under compromised efficiency, necessitating the investigation of the performance of alternative coagulants. Combining coagulants allows for the treatment process to take advantage of the different properties and efficiencies of each coagulant, and this can potentially result in synergistic performance (Xu et al., 2018). Therefore, there is a need to investigate the optimum addition sequences to achieve optimum pollutant removal.

A previous study demonstrated that adding polyferric chloride before polyamine favoured efficient colour removal for synthetic disperse yellow 201, while the reverse dosing order favoured synthetic reactive red 24 (Chen et al., 2010). However, optimal colour removal efficiency (97.5\%) was achieved at $\mathrm{pH} 6$ for both dyes. Another study compared the performance of aluminium and ferric-based coagulants as pre-treatment for $\mathrm{UVC} / \mathrm{H}_{2} \mathrm{O}_{2}$ treatment of wastewater (Umar et al., 2016).

\section{CORRESPONDENCE}

Nhamo Chaukura

\section{EMAIL}

nchaukura@gmail.com

nhamo.chaukura@spu.ac.za

\section{DATES}

Received: 5 June 2020

Accepted: 15 April 2021

\section{KEYWORDS}

chitosan

coagulation

ferric chloride

raw water

water pollution

\section{COPYRIGHT}

() The Author(s)

Published under a Creative Commons Attribution 4.0

International Licence

(CC BY 4.0) 
The results indicated that ferric-based coagulants were generally more effective than aluminium sulphate. Other researchers have investigated the effectiveness of individual and dual coagulants in the removal of microalgae from seawater using chitosanaluminium sulphate/ferric chloride (Loganathan et al., 2018). Ferric chloride coagulants had superior process performance in comparison to aluminium sulphate and chitosan-based individual coagulants. In terms of dual coagulation, using aluminium sulphate as coagulant and chitosan as flocculant improved microalgae removal efficiency.

Although numerous studies have been reported on the use of coagulants, there are no comparative studies on their performance on raw water, particularly in Zimbabwe. This study aimed to investigate optimum conditions for ferric chloride, chitosan and aluminium chloride in raw water samples from a local WTP, and compare their performance with aluminium sulphate, which is used at the WTP. The specific objectives were: (i) to determine the optimum dosage and $\mathrm{pH}$ for ferric chloride, aluminium chloride and chitosan, singly and in combination, (ii) to determine the most effective dosage strategy for combined coagulants (order of adding coagulants), and (iii) to compare the performance of the coagulants with that of aluminium sulphate.

\section{MATERIALS AND METHODS}

\section{Materials}

Chemical reagents used in the study were of analytical grade and were used without further purification. Aluminium chloride (A) (99\%, Associated Chemical Enterprises), ferric chloride (B) (66\%, Associated Chemical Enterprises), and chitosan (C) (LMW, Sigma Aldrich) were used as coagulants in this study. The acids used were acetic acid (99\%, Merck), hydrochloric acid (32\%, Glassworld), and nitric acid (55\%, Skylabs), and the alkali was sodium hydroxide ( $98 \%$, Acechem). Calcium carbonate (99\%, Acechem) and magnesium metal (99\%, Glassworld) were used to prepare stock solutions for determining the water hardness.

\section{Sampling and preparation of coagulant stock solutions}

The study area was described in detail elsewhere (Chaukura et al., 2020). Briefly, the WTP is fed from a river and two dams, uses the conventional water treatment process, and has a daily output of 14.4 ML. On average, the raw water had a $\mathrm{pH}$ of 6.65 , conductivity $307 \mu \mathrm{S} / \mathrm{m}$, turbidity $15.34 \mathrm{NTU}$, and total dissolved solids (TDS) $156 \mathrm{mg} / \mathrm{L}$. Using 5-L HDPE bottles, water samples were collected from the raw water feed point at the WTP. The water samples were transported to the laboratory for experimentation and stored at $4^{\circ} \mathrm{C}$. Prior to jar test experiments, stock solutions of the coagulants were freshly prepared by dissolving a certain amount of coagulant in a suitable solvent, and making up to the mark in a $1000 \mathrm{~mL}$ volumetric flask. Specifically, $1000 \mathrm{mg} / \mathrm{L}$ stock solution of $\mathrm{A}(\mathrm{pH}=2.6)$ was prepared using $1 \mathrm{~g}$ of $\mathrm{AlCl}_{3}$, while $\mathrm{B}$ $(1000 \mathrm{mg} / \mathrm{L}, \mathrm{pH}=2.1)$ ) was prepared using $1 \mathrm{~g}$ of $\mathrm{FeCl}_{3}$. A stock solution of $\mathrm{C}(100 \mathrm{mg} / \mathrm{L}, \mathrm{pH}=2.5)$ was prepared by dissolving $0.1 \mathrm{~g}$ of chitosan in $1 \%$ acetic acid and topping up to the mark in a $1000 \mathrm{~mL}$ volumetric flask with de-ionized water.

\section{Jar tests}

The coagulation experiments were carried out on raw water samples in triplicate using jar testing apparatus (Fig. 1a) following the method described by Ayekoe et al. (2017). Briefly, each jar was filled with $500 \mathrm{~mL}$ of raw water and a specified amount of coagulant stock solution was added to each jar, resulting in the desired dosage $(40,50,60,70,80,90 \mathrm{mg} / \mathrm{L}$ for $\mathrm{A}$ and $\mathrm{B}$, and 0.2 , $0.4,0.6,0.8,1.0,1.2 \mathrm{mg} / \mathrm{L}$ for $\mathrm{C}$ ) at room temperature. The choice

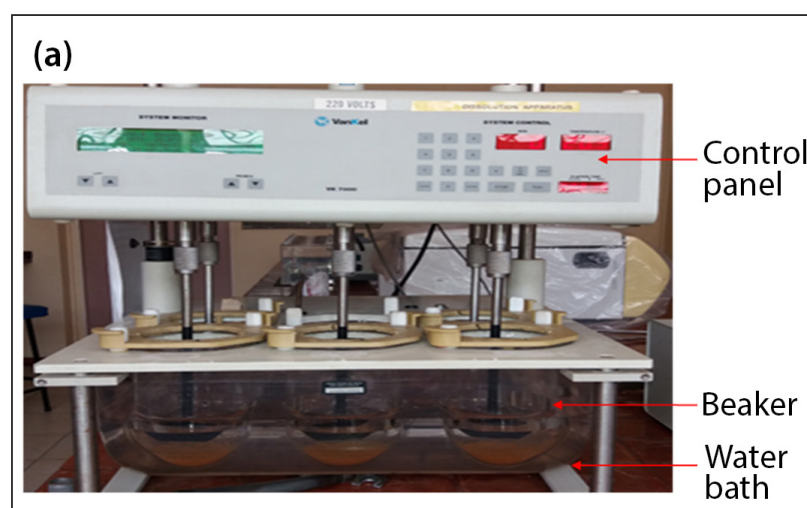

(b)

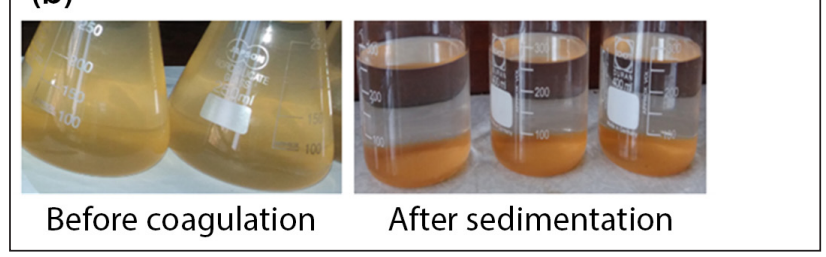

Figure 1. Coagulation experiment set up showing (a) jar-testing apparatus, and (b) water sample before coagulation and after sedimentation

of experimental values was guided by literature (Ammary and Cleasby, 2004) and preliminary studies not reported here. The samples were mixed rapidly at a velocity gradient of $10^{2} \mathrm{~s}^{-1}$ for $3 \mathrm{~min}$, following which the velocity gradient was reduced to $2 \mathrm{x}$ $10^{1} \mathrm{~s}^{-1}$ for a further $15 \mathrm{~min}$. Thereafter the flocs were allowed to settle for $30 \mathrm{~min}$ (Fig. 1b), and an aliquot of the supernatant solution was withdrawn from approximately $3 \mathrm{~cm}$ below water surface, filtered and analysed for different parameters.

The optimum $\mathrm{pH}$ for the coagulants was determined by applying a fixed coagulant dose to the raw water basing on the results obtained after the dosage optimization. The optimum coagulant dosage obtained at the coagulation stage was used as the fixed dosage. The $\mathrm{pH}$ of the solution at optimum dosage for $\mathrm{A}, \mathrm{B}$, and $\mathrm{C}$ was $7.09,7.13$ and 6.97 , respectively. The $\mathrm{pH}$ of raw water was adjusted to $4,5,6,7,8$ and 9 using $0.1 \mathrm{M} \mathrm{HCl}$ or $0.1 \mathrm{M}$ $\mathrm{NaOH}$ as appropriate. The same procedure used for dosage and $\mathrm{pH}$ optimization was used for combined coagulants. The dual coagulants were added in succession, 2 min apart at the rapid mixing stage. The coagulants were added in different orders and the operations coded differently. For example, when A was added before $B$ the process was coded $A / B$, and $B / A$ when $B$ was fed before A. Different coagulation combinations were investigated (Table 1).

The removal efficiencies $(r)$ for the water parameters in the study were calculated using Eq. 1 (Ang et al., 2016):

$$
r=\frac{C_{i}-C_{f}}{C_{i}} \times 100
$$

where $C_{i}$ and $C_{f}$ are the initial concentration of parameters in untreated, and the final concentration in treated water samples, respectively.

Table 1. Experimental design for coagulant combinations

\begin{tabular}{cccc}
\hline & A & B & C \\
\hline A & $A / A$ & $B / A$ & $C / A$ \\
$B$ & $A / B$ & $B / B$ & $C / B$ \\
$C$ & $A / C$ & $B / C$ & $C / C$ \\
\hline
\end{tabular}

$A=$ aluminium chloride, $B=$ ferric chloride, $C=$ chitosan 


\section{Analytical methods}

To assess the performance of coagulants, the physicochemical characteristics of water were determined before and after the coagulation process for each run. The turbidity and $\mathrm{pH}$ were measured using a turbidity meter (Orbeco-Hellige, 966, USA), and $\mathrm{pH}$ meter ( $\mathrm{pH}$ 700, Euetech Instruments, Singapore), respectively. Conductivity and TDS were determined using a multimeter (Cyberscan con 11, Euetech Instruments, Singapore), and optical absorbances were measured in the wavelength range 200-850 nm using a UV-Vis spectrophotometer (EVO300PC, Thermo Fisher Scientific, USA). Water hardness (Ca and Mg) was determined using a flame atomic absorption spectrometer (FAA6701F, Shimadzu, Japan).

\section{Statistical analysis}

Optimization studies were carried out by investigating the effect of 2 variables - coagulant dosage and $\mathrm{pH}$ - using two-way analysis of variance. Minitab 18 software was used to design and analyse the response, in order to measure the effect of turbidity on the coagulation process. The coagulation process was optimized using response surface methodology (RSM) and the adequacy of the optimization process was evaluated using analysis of variance (ANOVA).

\section{RESULTS AND DISCUSSION}

\section{Effect of coagulant dosage}

The turbidity removal efficiency for the coagulants increased with increasing coagulant dosage until it reached a plateau, beyond which there was a decrease in the removal efficiencies (Fig. 2). This decrease was attributed to the re-stabilization of colloidal particles when coagulant dosage exceeded the optimum value (Sun et al., 2010). The optimum dosages for A, B, and C were 50, 60 and $0.6 \mathrm{mg} / \mathrm{L}$, achieving turbidity removal efficiencies of 94.7,
95.7 and $94.4 \%$, respectively. In all cases, the conductivity and TDS removal efficiencies decreased gradually as the coagulant dose increased. Since ionic species act as charge carriers in solution, a drop in conductivity confirmed removal of these ions by the coagulation process. Similar observations are reported in literature (Matilainen et al., 2010). The $\mathrm{UV}_{254}$ removal efficiency increased moderately up to $60 \mathrm{mg} / \mathrm{L}$ as the dosage of A increased, then decreased slightly thereafter (Fig 2a). There were fluctuations in the $\mathrm{UV}_{254}$ removal efficiencies for B and C (Fig. 2b,c) as the doses were increased. Coagulant $\mathrm{C}$ achieved a $\mathrm{UV}_{254}$ removal efficiency of $58.2 \%$ with an optimum dosage of $0.6 \mathrm{mg} / \mathrm{L}$, while $\mathrm{B}$ attained a $\mathrm{UV}_{254}$ removal efficiency of $62.2 \%$ with a dosage of $50 \mathrm{mg} / \mathrm{L}$. $\mathrm{UV}_{254}$ is an important parameter for characterizing aromatic organics in water (De Oliveira et al., 2018). The results indicate that the coagulants can effectively reduce the concentration of aromatic compounds in the source water.

For dual coagulants, the order of performance in turbidity removal was: turbidity: $\mathrm{A} / \mathrm{C}>\mathrm{A} / \mathrm{B}>\mathrm{C} / \mathrm{B}>\mathrm{B} / \mathrm{A}>\mathrm{C} / \mathrm{A}>\mathrm{B} / \mathrm{C}$, conductivity was removed in the order: $\mathrm{C} / \mathrm{B}>\mathrm{A} / \mathrm{C}>\mathrm{C} / \mathrm{A}>\mathrm{B} / \mathrm{C}$ $>\mathrm{A} / \mathrm{B}>\mathrm{B} / \mathrm{A}$, TDS: $\mathrm{B} / \mathrm{C}>\mathrm{C} / \mathrm{A}>\mathrm{C} / \mathrm{B}>\mathrm{A} / \mathrm{C}>\mathrm{A} / \mathrm{B}>\mathrm{B} / \mathrm{A}$, and $\mathrm{UV}_{254}: \mathrm{B} / \mathrm{C}=\mathrm{B} / \mathrm{A}>\mathrm{A} / \mathrm{B}=\mathrm{A} / \mathrm{C}>\mathrm{C} / \mathrm{A}>\mathrm{C} / \mathrm{B}$. According to the findings, the order in which coagulants are added has an effect on the coagulation performance. Addition of inorganic coagulants prior to polymers neutralizes the negative suspended particles, leading to the formation of micro-flocs which are then adsorbed to the polymer particles (Ammary and Cleasby, 2004; Sun et al., 2010). However, the addition of polymeric coagulants before inorganics provides a base structure for the formation of flocs while the inorganic coagulants remove the remaining particles (Ammary and Cleasby, 2004). Overall, the results indicated that best performance was achieved by adding inorganic coagulants first, followed by the polymeric coagulant (C), with conductivity being the exception. Chitosan is reported in literature to be a good coagulant aid (Hesami et al., 2014).

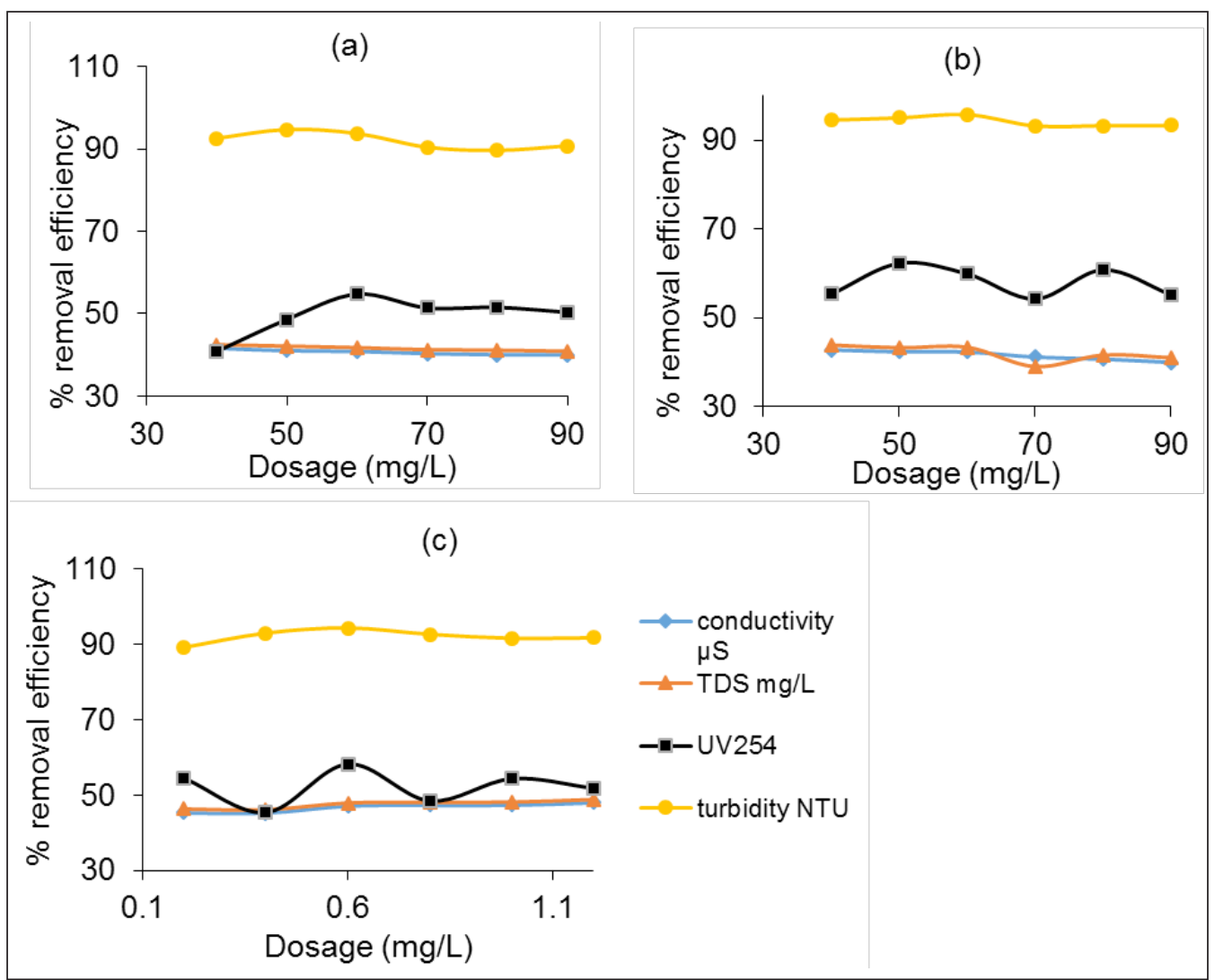

Figure 2. Effect of coagulant dose change on turbidity, $\mathrm{UV}_{254}$, conductivity and TDS removal efficiencies using (a) A, (b) $B$, and (c) C 


\section{Effect of $\mathrm{pH}$ on coagulation}

The raw water $\mathrm{pH}$ was 6.65 . There was a decrease in $\mathrm{pH}$ with increasing dosage for single coagulants (Fig. 3a,b), while for dual coagulants, final $\mathrm{pH}$ was dependent on the order in which coagulants were added, especially for the inorganic/organic coagulant combinations (Fig. 3c). The final $\mathrm{pH}$ for dual coagulants rose as the initial $\mathrm{pH}$ was increased from 4 to 9 . It is reported in literature that the resultant $\mathrm{pH}$ is dependent on the type of coagulant (inorganic or organic) and the dosage used. Coagulants (such as inorganics) which consume alkalinity can lead to a reduction in $\mathrm{pH}$. When using dual coagulants, the order in which they are added plays a key role in the resultant pH (Naceradska et al., 2019).

According to WHO guidelines, the acceptable $\mathrm{pH}$ range for drinking water is between 6.5 and 8.5 , hence the $\mathrm{pH}$ of water is usually adjusted to fall in this range (WHO, 2017). The final water $\mathrm{pH}$ decreased with increasing coagulant dosage for single coagulants (Fig. 4c). For dual coagulants, the $\mathrm{pH}$ after coagulation is consistently below this range. This could be due to the combined effect of metal-based coagulants in the case of $\mathrm{A} / \mathrm{B}$ and $\mathrm{B} / \mathrm{A}$, and the combination of an organic coagulant and inorganic coagulant in the case of $A / C, C / A, B / C$, and $C / B$ (Chen et al., 2018). It further points to the need for $\mathrm{pH}$ adjustment following coagulation. The decrease in supernatant $\mathrm{pH}$ when metal-based coagulants were used, is due to formation of hydrolysis species, leaving the $\mathrm{H}^{+}$ions in solution (Yonge, 2011). The formation of hydroxide precipitates suggests that sweep flocculation was likely to be the main coagulation mechanism in this investigation (Eslami et al., 2019). Bridging was probably the main coagulation mechanism when chitosan was used since charge neutralization is supported by a rise in $\mathrm{pH}$ due to protonation of $\mathrm{C}$, therefore consuming the $\mathrm{H}^{+}$ions (Rustøen, 2015). The resulting supernatant $\mathrm{pH}$ for combined coagulants was in the range of 5.4 to 6.0 and the order for $\mathrm{pH}$ decrease was: $\mathrm{B} / \mathrm{C}>\mathrm{A} / \mathrm{B}>\mathrm{C} / \mathrm{B}>\mathrm{A} / \mathrm{C}>$ $\mathrm{C} / \mathrm{A}>\mathrm{B} / \mathrm{A}$. The $\mathrm{pH}$ for treated samples in $\mathrm{pH}$ optimization studies fluctuated when single coagulants were used (Fig. 4a), while a steady increase was observed for dual coagulants (Fig. 4b).

\section{Single coagulants}

The turbidity removal efficiency for A (Fig. 5a) increased moderately as the $\mathrm{pH}$ of water was increased from 4 to 7 , then decreased gradually thereafter. The optimum $\mathrm{pH}$ for $\mathrm{A}$ was 7 . A similar trend was observed for B (Fig. 5b), which attained a turbidity removal efficiency of $95.6 \%$ at $\mathrm{pH}$ 6. Using $\mathrm{C}$, the turbidity removal efficiency decreased slightly between $\mathrm{pH} 4$ and 5 (Fig. $5 \mathrm{c}$ ) then increased gradually up to $\mathrm{pH} 7$ before dropping again. Coagulant $\mathrm{C}$ is effective in acidic conditions (Rustøen, 2015), a result confirmed by this study. The $\mathrm{UV}_{254}$ removal efficiency for A increased sharply between $\mathrm{pH} 4$ and 5, while the opposite trend was observed for TDS and conductivity removals (Fig. 5d). Similar trends were observed for $\mathrm{B}$ and $\mathrm{C}$ in the $\mathrm{pH}$ range 4 to 6 , and 4 to 5 , respectively (Fig. 5e,f). The results suggest attachment of the polymer chains of $\mathrm{C}$ to the pollutant forming bridges, a process called bridging, could be the dominant coagulation mechanism for $\mathrm{C}$, while aggregation through entrapment of particles, called sweep flocculation, dominated in the case of inorganic coagulants (Zhang et al., 2018; Eslami et al., 2019).

\section{Dual coagulants}

For the dual coagulants $A / B$, there was a gradual increase in turbidity, conductivity and TDS removal efficiencies as the $\mathrm{pH}$ of the water increased from $\mathrm{pH} 4$ to 8 . Beyond $\mathrm{pH} 8$, there was a steady decrease in the removal efficiencies (Fig. 5d). Solution $\mathrm{pH}$ influences the charge of the solute, and this determines the efficiency of the coagulation process. The optimum $\mathrm{pH}$ for the dual coagulants was higher compared to either single coagulant. A similar trend was observed in the conductivity and TDS removal efficiencies using $\mathrm{A} / \mathrm{C}$ combination (Fig. 5e). However, the highest turbidity removal efficiency $(95.9 \%)$ was achieved at $\mathrm{pH} 6$ for the $\mathrm{A} / \mathrm{C}$ combination, perhaps because $\mathrm{C}$ is more effective under acidic conditions (Bergamasco et al., 2009; Lurling et al., 2007). With the $\mathrm{B} / \mathrm{C}$ combination, the optimum $\mathrm{pH}$ was 7 (Fig. 5f). At this $\mathrm{pH}$, the protonated amino groups of $\mathrm{C}$ interact with negatively charged components of the raw water allowing effective coagulation (Lurling et al., 2007). At alkaline $\mathrm{pH}$ there is interference from anions in water, which will surround the positively charged amino groups preventing coagulation (Lurling et al. 2007). Overall, combined coagulants performed better than single coagulants, most likely due to their synergistic effect.

One of the most important factors that influence coagulation performance as well as mechanisms is $\mathrm{pH}$. When the $\mathrm{pH}$ of the system is acidic, the $\mathrm{H}^{+}$may compete with the coagulants forming bonds with the negatively charged colloids, while at basic $\mathrm{pH}$ the $\mathrm{OH}^{-}$ions may compete with the negatively charged colloids to bond with coagulant, hence reducing the concentration of coagulants which bond with colloids (Lek et al., 2018).

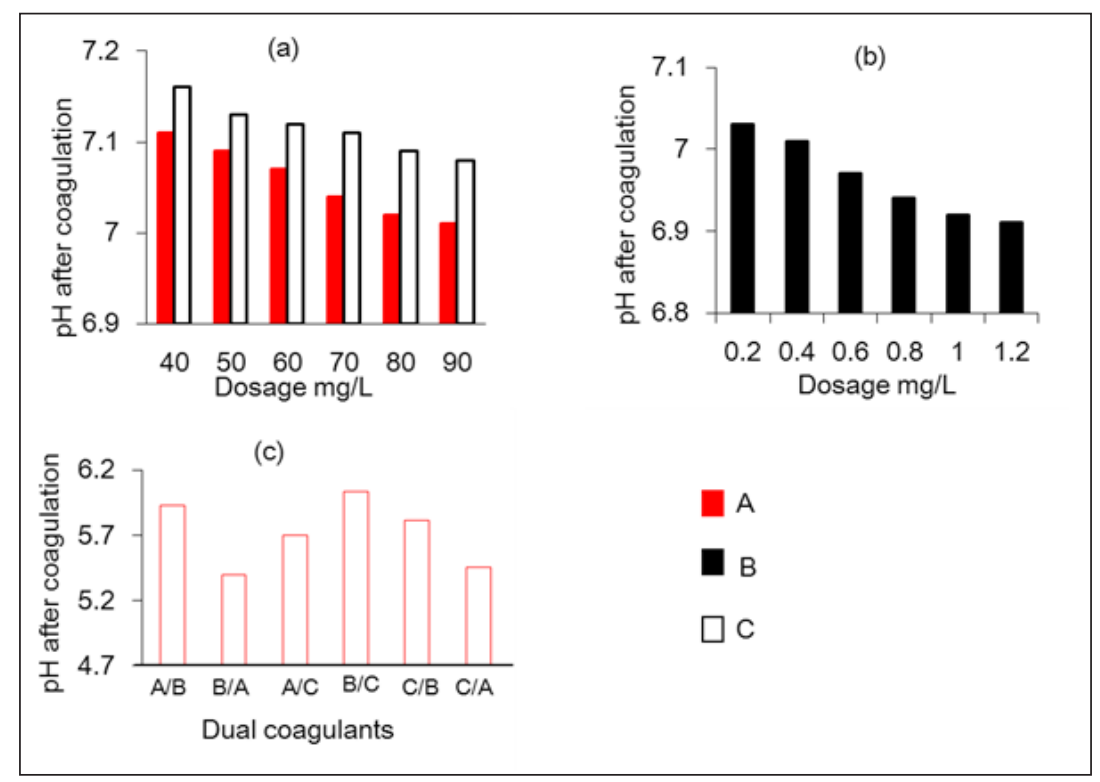

Figure 3. Changes in pH of water treated with single coagulants, (a) aluminum chloride and ferric chloride, and (b) chitosan; and dual coagulants, (c) $A / B, A / C$, and $B / C$ 


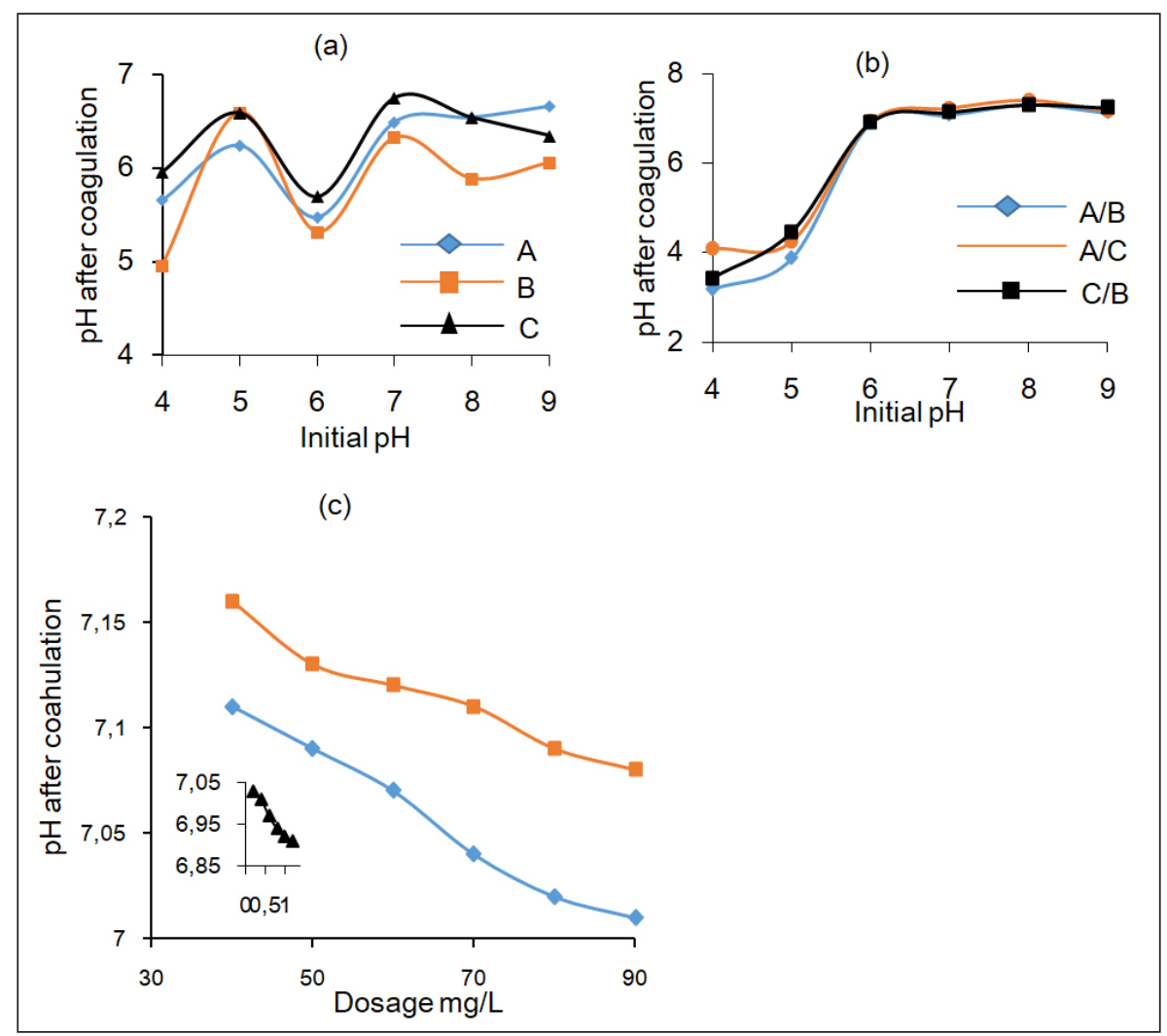

Figure 4. Changes in final $\mathrm{pH}$ with increase in initial $\mathrm{pH}$ using (a) single coagulants, (b) dual coagulants, and (c) the variation of pH with dosage
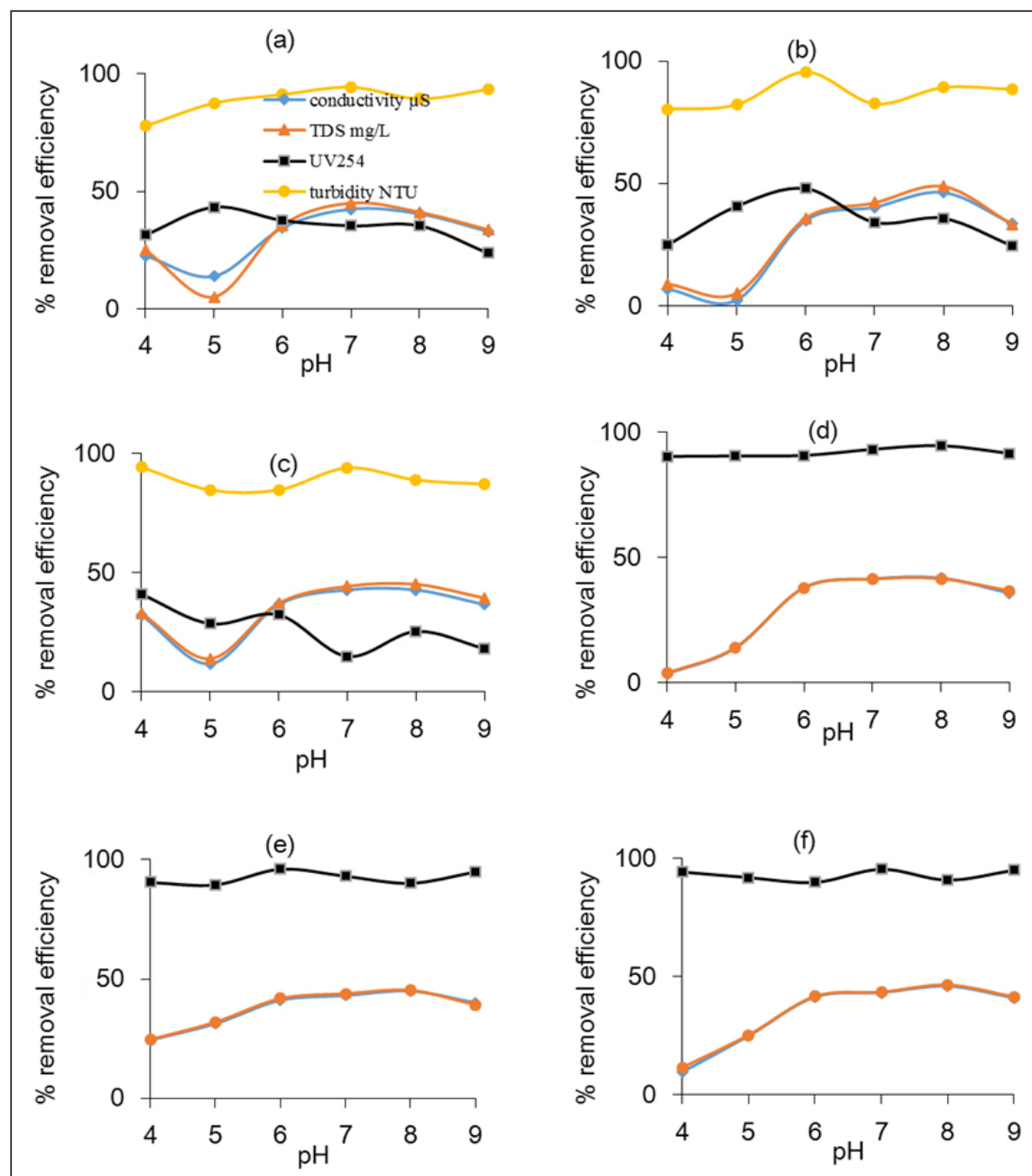

Figure 5. Effect of $\mathrm{pH}$ on turbidity, $\mathrm{UV}_{254}$, conductivity and TDS removal efficiencies using single coagulants: (a) $\mathrm{A}$, (b) $\mathrm{B}$, and (c) $\mathrm{C}$ as coagulants, and dual coagulants: (d) $A / B$, (e) $A / C$, and (f) $B / C$ 
The $\mathrm{pH}$ of water also affects the hydrolysis products of coagulants; therefore, it has a significant influence on the coagulation process. Although the chemistry of ferric-based coagulants in aqueous systems is complex, since many species are generated at different $\mathrm{pH}$ values, solubility diagrams may possibly be useful in estimating the optimum coagulant dosage under different operating conditions (Johnson and Amirtharajah, 1983; Silanpaa et al., 2018). Ideally, the $\mathrm{pH}$ range for the hydrolysis of alum is 5.57.7 (Johnson and Amirtharajah, 1983). Under optimum $\mathrm{pH}$, there is minimal solubility and most of the coagulant forms floc. At $\mathrm{pH}$ lower than optimum $\mathrm{pH}$, positively charged dissolved $\mathrm{Al}$ species form. When the $\mathrm{pH}$ exceeds the optimal value, more negatively charged $\mathrm{Al}$ species are generated. Outside the optimal $\mathrm{pH}$ range, particularly at $\mathrm{pH} 3$ and 11, the destabilization potential will be greatly lowered, hence the smaller particulates will not coalesce to form large flocs, but rather remain in solution (Silanpaa et al., 2018). It is intriguing to note that at an initial $\mathrm{pH}$ of 6 all coagulant reduces $\mathrm{pH}$ marginally but when dosed together in $5 \mathrm{~b}$ at the same initial $\mathrm{pH}$, they increase $\mathrm{pH}$. This deserves further research.

\section{Ultraviolet-visible absorbance}

A steady decrease in UV-vis absorbance was observed from raw water to treated water for all samples, indicating the decrease in organic compounds during the coagulation processes. A decrease in UV-vis absorbance indicates removal of chromophoric substances such as organic matter, which contribute to turbidity (Matilainen et al., 2010). Different wavelengths represent different types of organic particles; for example a wavelength of $254 \mathrm{~nm}$ represents aromatic compounds, $272 \mathrm{~nm}$ shows the potential for DBPs formation and $456 \mathrm{~nm}$ indicates color ( $\mathrm{Ng}, 2013$; Tshindane et al., 2019). A pH of 6 resulted in the largest organic compound removal in the case of both $\mathrm{A}$ and $\mathrm{B}$, while the least removal was observed at $\mathrm{pH} 9$ (Fig. 6a,b). At this $\mathrm{pH}$, most organic compounds are protonated, and can thus interact with the charged coagulants to form flocs (Chen et al., 2010). Figure 6c shows the results obtained for Coagulant $\mathrm{C}$ under $\mathrm{pH}$ optimization studies, where
$\mathrm{pH} 4$ gave the least removal while the highest removal was observed at $\mathrm{pH}$ 7. Coagulant $\mathrm{C}$ does not carry an ionic charge, and therefore depends on dipole interactions with the organic matter (Ang et al., 2016). The dosage of $90 \mathrm{mg} / \mathrm{L}$ resulted in the largest decrease of organic content when Coagulant A was used, while the lowest removal was observed at $40 \mathrm{mg} / \mathrm{L}$ (Fig. 6d). For Coagulant B, the lowest removal was observed at a dosage of $40 \mathrm{mg} / \mathrm{L}$ while the highest removal efficiency was observed at $60 \mathrm{mg} / \mathrm{L}$ (Fig. 6e). The lowest removal efficiency for Coagulant $C$ was observed $0.2 \mathrm{mg} / \mathrm{L}$, while the highest removal was at $1.2 \mathrm{mg} / \mathrm{L}$ (Fig. 6f). This shows that Coagulant $\mathrm{C}$ is more effective than both Coagulants $\mathrm{A}$ and $\mathrm{B}$, mainly because, being organic, Coagulant $\mathrm{C}$ has more interaction with small charged particles and facilitates aggregation into flocs more efficiently (Sillanpaa et al., 2018). Previous studies have used Coagulant $\mathrm{C}$ as a flocculant aid in combination with Flocculant A and B separately (Loganathan et al., 2018; Sillanpaa et al., 2018). For dual coagulants, the organic content removal varied with wavelength; therefore the results may be used to deduce the effective coagulant combination at a particular wavelength. In all the cases, $\mathrm{pH} 7$ resulted in the highest organic content removal for dual coagulants during the $\mathrm{pH}$ optimization studies while $\mathrm{pH} 4$ produced the lowest removal (Fig. $6 \mathrm{~g}-\mathrm{i}$ ).

\section{Coagulant performance evaluation}

The order for removal efficiencies were (Table 2): turbidity: D > $\mathrm{B}>\mathrm{A}>\mathrm{C}$. TDS: $\mathrm{C}>\mathrm{D}>\mathrm{B}>\mathrm{A}$; conductivity: $\mathrm{C}>\mathrm{B}>\mathrm{D}>\mathrm{A}$. $\mathrm{UV}_{254}: \mathrm{D}>\mathrm{B}>\mathrm{C}>\mathrm{A}$. The optimum dose for $\mathrm{D}(80 \mathrm{mg} / \mathrm{L})$ was higher than that of $B(60 \mathrm{mg} / \mathrm{L})$, and $C(0.6 \mathrm{mg} / \mathrm{L})$. Basing on the findings, the performance of $\mathrm{A}, \mathrm{B}$, and $\mathrm{C}$ were satisfactory and comparable with that of $\mathrm{D}$. In a related study, other researchers established optimum coagulant doses of 40,80 , and $1 \mathrm{mg} / \mathrm{L}$ for aluminium sulphate, ferric chloride and chitosan, respectively, at $\mathrm{pH}$ 6. These variations in coagulant doses are related to the quality of raw water used. In their study, the raw water had high alkalinity $\left(>180 \mathrm{mg} \mathrm{CaCO}_{3} / \mathrm{L}\right.$ ) and low total organic carbon (TOC) $(<4.0 \mathrm{mg} / \mathrm{L})$ (Rizzo et al., 2008). Hence, it is of great importance

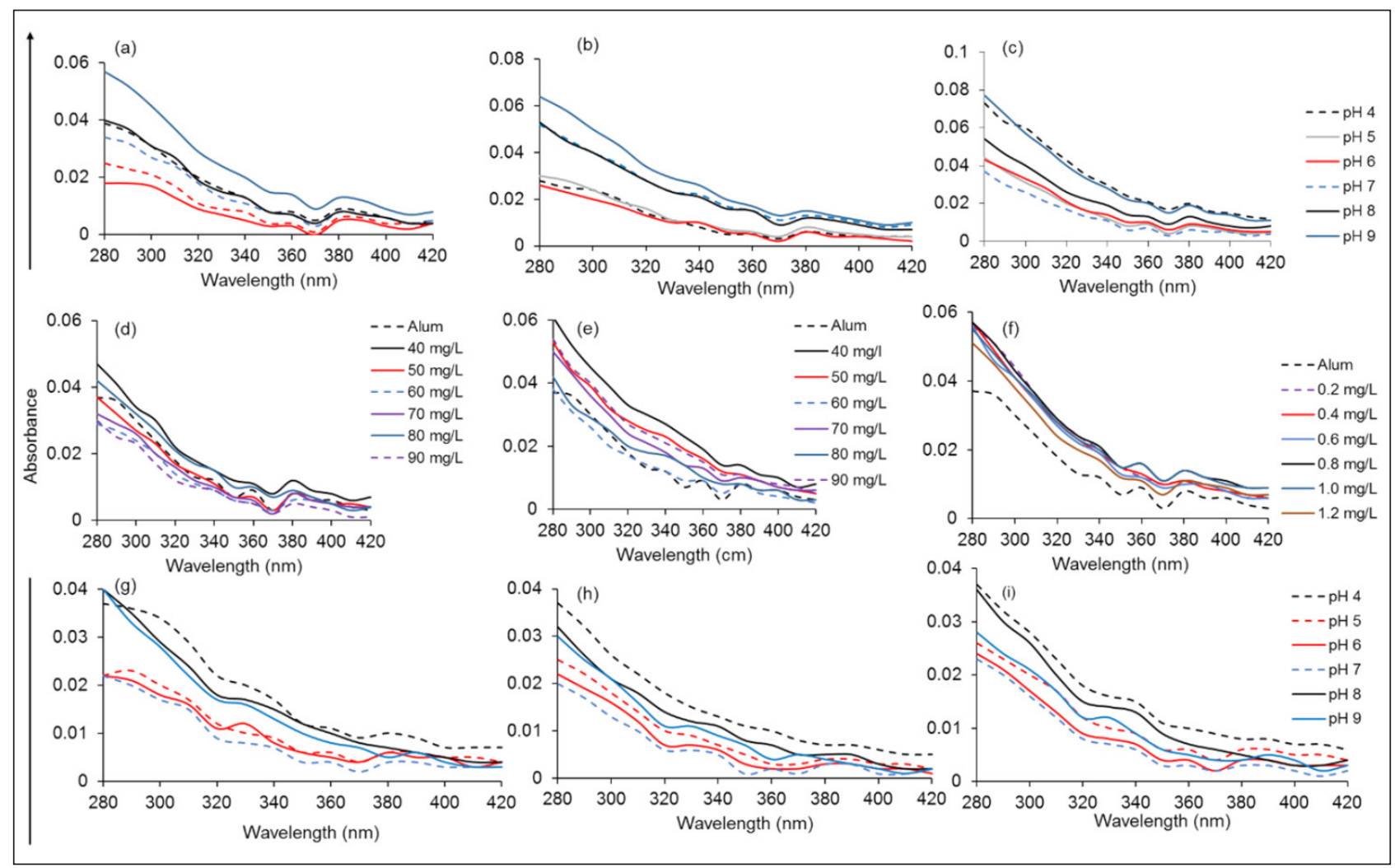

Figure 6. Ultraviolet absorbance spectra showing effect of pH using (a) A, (b) B, (c) C; dosage optimization for (d) A, (e) B, (f) C; and pH optimization for (g) $A / C$, (h) $A / B$, and (i) $C / B$ 
Table 2. Removal efficiencies (\%) for Coagulants A, B, C, and D at their optimum dosages

\begin{tabular}{lcccc}
\hline & D & C & B & A \\
\hline Dose mg/L & 80.0 & 0.6 & 60.0 & 50.0 \\
Turbidity (NTU) & $96.7 \pm 0.42$ & $94.4 \pm 0.38$ & $95.7 \pm 0.33$ & $94.7 \pm 0.40$ \\
TDS (mg/L) & $45.8 \pm 0.30$ & $47.9 \pm 0.26$ & $43.3 \pm 0.41$ & $42.3 \pm 0.35$ \\
Conductivity ( $\mu$ S) & $41.7 \pm 0.32$ & $47.1 \pm 0.37$ & $42.2 \pm 0.35$ & $41.0 \pm 0.39$ \\
UV $_{254}$ & $73.5 \pm 0.44$ & $58.2 \pm 0.41$ & $59.8 \pm 0.36$ & $48.6 \pm 0.34$ \\
\hline
\end{tabular}

to know the raw water quality in order to establish the most suitable conditions for effective coagulation. The present study revealed that a much lower dose of ferric chloride is required in comparison to aluminium sulphate, and this potentially lowers the costs of operation. However, a detailed cost-benefit analysis is required to support results-based decision-making and conclusions. Used as dual coagulants, ferric chloride and chitosan resulted in the highest TDS and $U_{254}$. Previous studies have reported that chitosan serves as a good coagulant aid, and in particular was observed to reduce the dose of ferric chloride required in the treatment process (Hesami et al., 2014).

\section{CONCLUSION}

This study investigated the performance of three coagulants: aluminium chloride (A), ferric chloride (B), and chitosan (C) in drinking water treatment in order to improve efficiency of the coagulation process. The results demonstrated removal efficiency decreased in the order: $\mathrm{B}>\mathrm{A}>\mathrm{C}$. The optimum $\mathrm{pH}$ for the single coagulants was acidic. Combined coagulants gave better removal efficiencies than single coagulants with maximum removal efficiencies obtained with the $\mathrm{A} / \mathrm{C}$ combination. The optimum $\mathrm{pH}$ for combined coagulants was acidic, except when using the A/B combination. Overall, the coagulants presented satisfactory removal efficiencies, hence they are viable alternatives to $\mathrm{D}$ in treating drinking water. Aluminium coagulants are known to generate secondary products in treated water, and these have adverse human health effects. Since $\mathrm{C}$ is non-toxic and safe to ingest, it can potentially be used at household level for point-ofuse water treatment in combination with other techniques.

The study showed that, in comparison to aluminium sulphate, a lower dose of ferric chloride is required, and this potentially reduces operation costs. However, a detailed cost-benefit analysis is required to support decision making. Future research should investigate the efficiency of combining the three coagulants and discovering the best dosing strategy. The removal of organic matter has been indicated by $\mathrm{UV}_{254}$ in this study. Dissolved organic matter is an influencing factor in the coagulation process, thus the effectiveness in DOC removal by the different coagulant schemes would be interesting to investigate further.

\section{AUTHOR CONTRIBUTIONS}

NC conceptualized the idea, TAM collected and analysed data, HHM helped in data analysis, and RTT carried out statistical analysis. All authors contributed equally to manuscript writing.

\section{FUNDING}

This work was partially supported by the National Research Foundation of South Africa [Grant UID: 112013, 2018-2019].

\section{ORCID}

Nhamo Chaukura

https://orcid.org/0000-0001-7797-6915

\section{REFERENCES}

ALSHIKH O (2007) Parameters affecting coagulation/flocculation of drinking water under cold temperatures. Master's thesis, University of Windsor.

AMMARY BY and CLEASBY JL (2004) Effect of addition sequence on dual coagulant performance. Am. Water Works Ass. 96 (2) 90-101.

ANG WL, MOHAMMED AW, BENAMOR A and HILAL N (2016) Chitosan as natural coagulant in hybrid coagulant-nanofiltration membrane process for water treatment. J. Environ. Chem. Eng. 4 (4) 4857-4862. http://dx.doi.org/10.1016/j.jece.2016.03.029

AYEKOE CYP, ROBERTA D and GONE LD (2017) Combination of coagulation-flocculation and heterogeneous photocatalysis for improving the removal of humic substances in real treated water from Agbô River (Ivory-Coast). Catal. Today. 281 2-13. http:// dx.doi.org/10.1016/j.cattod.2016.09.024

BAIRWA P (2016) A comparative study of natural and chemical coagulants in water treatment. Master's thesis, National Institute of Technology Kurukshetra.

BERGAMASCO R, BOUCHARD C, DA SILVA FV, REIS MHM and FAGUNDES-KLEN MR (2009) An application of chitosan as a coagulant/flocculant in a microfiltration process of natural water. Desalination. 245 205-213. https://doi.org/10.1016/j.desal.2008.04.049

CHAUKURA N, MOYO W, INGWANI T, NDIWENI SN, GWENZI W and NKAMBULE TI (2020) Comparative removal efficiencies of natural organic matter by conventional drinking water treatment plants in Zimbabwe and South Africa. Water Environ. Res. 1-12 2020. https://doi.org/10.1002/wer.1459

CHEN T, GAO B and YUE Q (2010) Effect of dosing method and pH on colour removal performance and floc aggregation of polyferric chloride-polyamine dual-coagulant in synthetic dyeing wastewater treatment. Colloids Surf. A: Physicochem. Eng. Aspects. 355 121-129.

CHEN S, YUAN Z, HANIGAN D, WESTERHOFF P, ZHAO H and NI J (2018) Coagulation behaviours of new covalently bound hybrid coagulants $(\mathrm{CBHyC})$ in surface water treatment. Sep. Purif. Technol. 192 322-328. http://doi.org/10.1016/j.seppur.2017.10.036

DE OLIVEIRA GF, BERTONE E, STEWART RA, AWAD J, HOLLARD A, O'HALLORAN K and BIRD S (2018) Multi-Parameter compensation method for accurate in situ fluorescent dissolved organic matter monitoring and properties characterization. Water. 10 (9) 1146.

ESLAMI H, EHRAMPOUSH MH, ESMAEILI A, SALMANI MH, EBRAHIMI AA, GHANEIAN MT, FALAHZADEH H and FARD RF (2019) Enhanced coagulation process by Fe-Mn bimetal nanooxides in combination with inorganic polymer coagulants for improving As(V) removal from contaminated water. J. Clean. Prod. 208 384-392. https://doi.org/10.1016/j.jclepro.2018.10.142

HESAMI F, BINA B and EBRAHIMI A (2014) The effectiveness of chitosan as a coagulant aid in turbidity removal from water. Int. J. Environ. Health Eng. 3 8. http://doi.org/10.4103/2277-9183.131814

HOWLADAR MF (2017) An assessment of surface water chemistry with its possible sources of pollution around the Barapukuria Thermal Power Plant impacted area, Dingpur, Bangladesh. Groundwater Sustainable Dev. 5 38-48. http://doi.org/10.1016/j.gsd.2017.03.004

JOHNSON PN, AMIRTHARAJAH A (1983) Ferric chloride and alum as single and dual coagulants. J. Am. Water Works Ass. 75 (5) 232-239.

JUSTINA MD, MUNIZ BRB, BRORING MM, COSTA VJ and SKORONSKI E (2018) Using vegetable tannin and polyaluminium chloride as coagulants for dairy wastewater treatment: A comparative study. J. Water Process Eng. 25 173-181. http://doi.org/ 10.1016/j.jwpe.2018.08.001

LEK BLC, PETER AP, CHANG KHQ, RAGU P, SETHU V, SELVARAJOO A and ARUMUGASAMY SK (2018) Treatment of palm oil mill effluent (POME) using chickpea (Cicer arietinum) as a natural coagulant and flocculant: Evaluation, process optimization and characterization of chickpea powder. J. Environ. Eng. 6 (5) 6243-6255. http://doi.org/10.1016/j.jece.2018.09.038

LOGANATHAN K, SATHTHASIVAM J and SARP S (2018) Removal of microalgae from sea water using chitosan-alum/ferric chloride dual coagulants. Desalination. 433 25-32. http://doi.org/10.1016/j. desal.2018.01.012

LURLING M, NOYMA NP, DE MAGALHAE L, MIRANDA M, MUCCI M, VAN OOSTERHOUT F and MORINHO MM (2007) Critical assessment of chitosan as a coagulant to remove cyanobacteria. Harmful Algae. 66 1-12. http://doi.org/10.1016/j.hal.2017. 04.011 
LV M, ZHANG Z, ZENG J, LUI J, SUN M, YADAV RS and FENG Y (2019) Roles of magnetic particles in magnetic seeding coagulationflocculation process for surface water treatment. Sep. Purif. Technol. 212 337-343. http://doi.org/10.1016/j.seppur.2018.11.011

MATILAINEN A, VEPSALAINEN M and SILLANPAA M (2010) Natural organic matter removal by coagulation during drinking water treatment: A review. Adv. Colloid Interface Sci. 159 189-197. http://doi:10.1016/j.cis.2010.06.007

NACERADSKA J, PIVOKONSKY L and PIVOKONSKY M (2019) On the importance of $\mathrm{pH}$ value in coagulation. J. Water Suppl. J. Water Supply: Res. Technol. 68 (3) 222-230. http://doi.org/10.2166/ aqua.2019.155

NG M (2013) Characterization and removal of natural organic matter in drinking water treatment. PhD thesis, University of New South Wales.

RASHID A, KHATTAK SA, ALI L, ZAIB M, JEHAN S, AYUB M, ULLAH S (2019) Geochemical profile and source identification of surface and groundwater pollution of District Chitral, Northern Pakistan. Microchem. J. 145 1058-1065. http://doi.org/10.1016/j. microc.2018.12.025

RENAULT F, SANCEY B, BADOT PM, CRINI G (2009) Chitosan for coagulation/flocculation process - An ecofriendly approach. Eur. Polymer J. 45 (5) 1337-1348. http://doi.org/10.1016/j.eurpolymj. 2008.12.027

RIZZO L, DI GENNARO A, GALLO M and BELGIORNO V (2008) Coagulation/chlorination of surface water: A comparison between chitosan and metal salts. Sep. Purif. Technol. 62 (1) 79-85. https:// doi.org/10.1016/j.seppur.2007.12.020

RUSTOEN TL (2015) Efficiency of chitosan and alginate compared with a chemical precipitating agent in treating drilling fluids produced from road construction-A laboratory experiment. Master's thesis, Norwegian University of Life Sciences.

El SAMRANI AG, LARTIGES BS, MONTARGES-PELLETIER E, KAZPARD V, BARRES O and GHANBAJA J (2004) Clarification of municipal sewage with ferric chloride: the nature of coagulant species. Water Res. 38 756-768.

SILLANPAA M, NCIBI MC, MATILAINEN A and VEPSALAINEN M (2018) Removal of natural organic matter in drinking water treatment by coagulation: A comprehensive review. Chemosphere. 190 54-71. http://doi.org/10.1016/j.chemosphere.2017.09.113

SUN T, LIU LI, WAN LI and ZHANG YP (2010) Effect of silicon dose on preparation and coagulation performance of poly-ferric-aluminumsilicate-sulfate from oil shale ash. Chem. Eng. J. 163 (1-2) 48-54. http://doi.org/10.1016/j.cej.2010.07.037
TSHIDANE P, MAMBA PP, MOSS L, SAWANA UU, MOYO W, MOSTA MM, CHAUKURA N, MAMBA BB, and NKAMBULE TTI (2019) The occurrence of natural organic matter in South African water treatment plants. J. Water Process Eng. 31. http://doi.org/10.1016/j. jwpe.2019.100809

WANG Q and YANG Z (2016) Industrial water pollution, water environment and health risks in China. Environ. Pollut. 218358 365. http://doi.org/10.1016/j.envpol.2016.07.011

WEI H, GAO B, REN J, LI A and YANG H (2018) Coagulation/ flocculation in dewatering of sludge: A review. Water Res. 143 608631. http://doi.org/10.1016/j.watres.2018.07.029

WHO (World Health Organization) (2017) Guidelines for DrinkingWater Quality ( $4^{\text {th }}$ edn, incorporating the first addendum). World Health Organization, Geneva.

XU Q, WANG Q, ZHANG W, YANG P, DU Y and WANG D (2018) Highly effective enhancement of waste activated sludge dewaterability by altering proteins properties using methanol solution coupled with inorganic coagulants. Water Res. 138 181-191. https://doi.org/10.1016/j.watres.2018.03.038

YONGE DT (2011) A comparison of aluminium and iron based coagulants for treatment of surface water in Sarasota country, Florida. Master's thesis, University of Central Florida.

ZHANG Z, JING R, HE S, QIAN J, ZHANG K, MA G and CHANG $\mathrm{X}$ (2018) Coagulation of low temperature and low turbidity water: Adjusting basicity of polyaluminum chloride (PAC) and using chitosan as a coagulant aid. Sep. Purif. Technol. 206 131-139. http:// doi.org/10.1016/j.seppur.2018.05.051

ZHAO Y, XU M, LUI Q, WANG Z, ZHAO L and CHEN Y (2018) Study of heavy metals pollution, ecological risk and sources apportionment in the surface water and sediments of the Jiangsu coastal region, China: A case study of the Sheyang Estuary. Mar. Pollut. Bull. 137 601-609. http://doi.org/10.1016/j.marpolbul.2018.10.044

ZHOU Z, YANG Y, LI X, LI P, ZHANG T, LV X, LUI L, DONG J and ZHENG D (2018) Optimized removal of natural organic matter by ultrasound-assisted coagulation of recycling drinking water treatment sludge. Ultrasonics - Sonochem. 48 171-180.http://doi.org/ 10.1016/j.ultsonch.2018.05.022 